\title{
Marina Câmara'
}

\section{Giuseppe Penone, matéricoe transcendental}

Giuseppe Penone, matter and transcendence

Giuseppe Penone, materialista e trascendentale 


\title{
Resumo
}

A produção de Giuseppe Penone, apesar de majoritariamente vinculada ao âmbito tridimensional, não se restringe à realização de esculturas, performances, ações, fotografias, desenhos e instalações. Sua produção textual é igualmente expressiva. Seus escritos de artista foram reunidos e editados em 2009 sob o título Giuseppe Penone. Scritti 1968-2008, pelo Museo d'Arte Moderna di Bologna (MAMbo), então representado por Gianfranco Maraniello - organizador e prefaciador do volume -, em parceria com a Ikon Gallery de Birmingham, com direção de Jonathan Watkins. Os direitos de tradução dos escritos de Penone foram cedidos à autora do presente texto e a tradução está atualmente sendo revisada. A escrita de Penone é, como o próprio artista ressalta, uma condição para a existência de toda a sua obra. Apresentam-se aqui algumas traduções inéditas dos escritos de artista de Giuseppe Penone, antecedidas por um comentário da autora acerca dos principais norteadores da poética do artista.

Palavras-chave: Escritos de artista. Giuseppe Penone. Tradução.

\section{Abstract}

Giuseppe Penone's production, though majorly linked to the tridimentional domain, is not limited to the realization of sculptures, performances, actions, photographs, drawings and installations. His textual production is equally expressive. His artist's writings have been gathered and published in 2009 under the title of 'Giuseppe Penone Scritti 1968-2008', by the Museo d'Arte Moderna di Bologna (MAMbo), represented, then, by Gianfranco Maraniello - organizer and author of the volume's preface - , in partnership with the Birmingham based Ikon Gallery, directed by Jonathan Watkins. Penone's writings' translating rights have been given to the present text's author, and the translation is currently being reviewed. Penone's writing, as remarked by the artist himself, is a condition for the whole ensemble of his oeuvre's existence. We present, here, some of the yet unpublished translations of Giuseppe Penone's artist's writings, preceded by a comment, given by this author, concerning the main axis of the artist's poetic.

Key-words: Artist's writings. Giuseppe Penone. Translation.

\begin{abstract}
La produzione di Giuseppe Penone, nonostante sia soprattutto legata all'ambito del tridimensionale, non si limita alla realizzazione di sculture, performance, azioni, fotografie, disegni e installazioni. La sua produzione testuale è altrettanto espressiva. I suoi scritti d'artista sono stati pubblicati nel 2009 come "Giuseppe Penone. Scritti 1968-2008". La raccolta è stata a cura del Museo d'Arte Moderna di Bologna (MAMbo), allora rappresentato da Gianfranco Maraniello - organizzatore e autore della prefazione del volume -, in collaborazione con la Ikon Gallery di Birmingham, diretta da Jonathan Watkins. I diritti di traduzione degli scritti di Penone sono stati assegnati all'autrice di questo testo e la traduzione è attualmente in fase di revisione. La scrittura di Penone è, come sottolinea l'artista stesso, una condizione per l'esistenza di tutta la sua opera. Qui sono presentate alcune traduzioni inedite degli scritti d'artista di Giuseppe Penone, precedute da un commento dell'autrice sui principali orientamenti della poetica dell'artista.
\end{abstract}

Parole chiavi: Scritti d'artista. Giuseppe Penone. Traduzione.

\footnotetext{
$1 \quad$ Professora adjunta do Dpto de Artes Visuais do Instituto de Artes da UFRGS e pós-doutoranda no Dpto de Letras Modernas da Faculdade de Filosofia, Letras e Ciências Humanas da USP. http://lattes.cnpq. br/0869232948518117 Email: marina.camara@gmail.com
} 
O artista italiano Giuseppe Penone é responsável pela realização de uma das mais instigantes produções artísticas contemporâneas desde a segunda metade dos anos sessenta, quando foi membro da Arte Povera. Não tendo se obrigado a filiar-se nem à desordem própria ao movimento Informal dos anos 50, nem à ordem a qual foi reduzido o Minimalismo, a obra de Penone configura-se na constituição de um espaço comum entre homem e natureza, demonstrando que a única possibilidade é aquela da radical correspondência e mútua habitação entre os corpos do mundo. "Non c'è differenza tra uomini e natura" (informação verbal)": assim Penone sintetiza algumas das principais questões que são desdobradas em seus trabalhos. A pesquisa que o artista realiza com a natureza é frequente e, de certo modo, razamente atribuída ao fato de Penone ter vivido, durante os primeiros vinte anos de sua vida - idade em que começa a estudar e a produzir arte - em estreito contato com a floresta de Garessio, na província de Cuneo, região do Piemonte, na Itália, onde o artista nasceu. De fato, não há dúvidas de que para a construção poética deste artista, sentir o atravessamento do corpo pelo ambiente é imprescindível, mas esta especial relação com o meio é irredutível a memórias ou a aspectos biográficos.

Na seleção de escritos de artista aqui trazida, Penone, a partir de comentários acerca da noção de arte e suas "funções", fala sobre o princípio da identidade imprescindível entre elementos naturais e a realização do seu trabalho artístico.

Pesquisadora da obra de Giuseppe Penone há cerca de dez anos, participei junto ao artista da montagem em Inhotim de Elevazione, ainda hoje a única obra de sua autoria exposta permanentemente no Brasil; defendi em 2016, na Escola de Belas Artes da UFMG, a primeira tese brasileira que afronta integralmente o trabalho deste artista33; e desenvolvo, no Departamento de Letras Modernas da USP, a tradução dos seus escritos de artista. Ainda no mestrado, pesquisando a resistência a partir de obras que lidam de um modo outro com o tempo ${ }^{4}$, o encontro com a obra de Giuseppe Penone foi emblemático, sobretudo quando, ao terminarmos de montar Elevazione, ele disse: "Eccola! Vocês a verão pronta, eu não", referindo-se ao longo tempo que deveria ainda passar até que a escultura se complete, um tempo que estará provavelmente para além da própria duração da vida do artista, já que a previsão é que Elevazione precisa de mais pelo menos 30 anos para se completar.

\footnotetext{
2 Em conversa com o artista em agosto de 2011. Não há diferença entre homens e natureza, TN.

3 CÂMARA, Marina, Giuseppe Penone [manuscrito]: da história à pele do mundo - 2016. 211 f. : il. Orientador: Stéphane Denis Albert René Philippe Huchet. Tese (doutorado) - Universidade Federal de Minas Gerais, Escola de Belas Artes.

4 Cf. CÂMARA, Marina. Imagens do tempo: a inoperância como resistência na arte contemporânea. Dissertação (Mestrado) - Pontifícia Universidade Católica de Minas Gerais. Programa de Pós-Graduação em Comunicação Social. Belo Horizonte, 2012.
} 


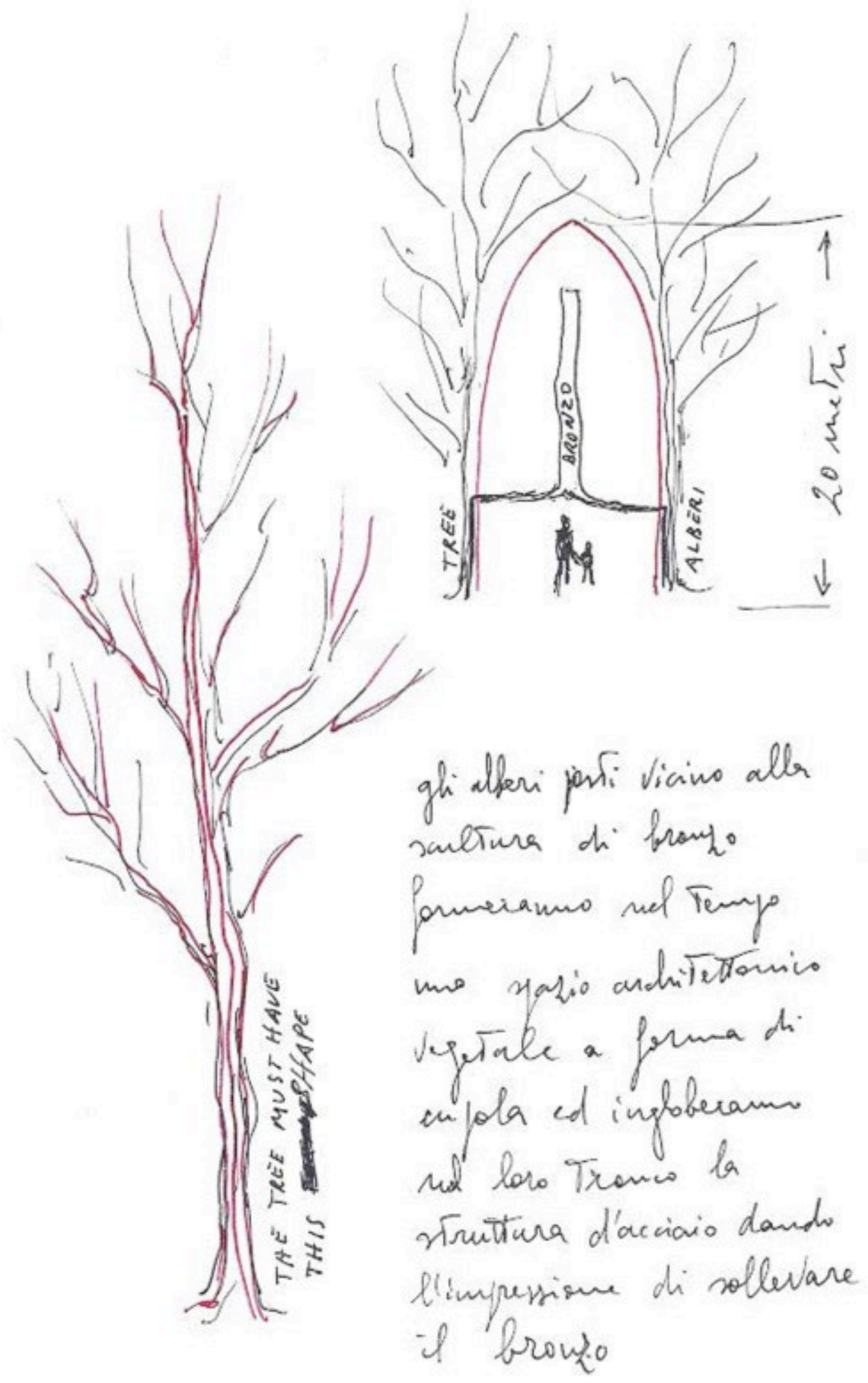

Figura 1. Giuseppe Penone. Desenho esquemático para montagem de Elevazione, 2011.Brumadinho. Fonte: Correspondência pessoal. 
Em uma entrevista ${ }^{5}$ que fizemos, eu e João Guilherme Dayrell, com o artista, em 2014, em seu estúdio em Turim, Penone comentou mais de uma vez sobre seu interesse acerca da tecnologia que existe na natureza ou, em outras palavras, sobre a cultura da natureza. Ao contextualizar o início de sua produção e dizer sobre a necessidade de redefinir a linguagem da arte que se colocava entre os anos 60 e 70, ele faz uma comparação com outros momentos da História da Arte em que "houve uma redefinição dos valores culturais e os artistas recomeçaram a partir da natureza enquanto objeto de análise e de interesse do ponto de vista formal, filosófico, naturalístico e científico." (PENONE, 2017, p.30). Apesar de reconhecer, em um momento seguinte da entrevista, que o interesse específico que ele nutre pela natureza é no sentido de conferir-lhe uma dignidade (palavra por ele usada), a fim de estabelecer com os elementos naturais uma relação de paridade, o artista não admite que se trata de uma visão animista do mundo. Ora, o que está em jogo em obras como Soffio (1975), não me parece ser senão o comportamento vital da folha na figura da sua respiração-fotossíntese. A mesma noção valeria para Elevazione e o devir escultura das árvores a quem o artista atribui a coautoria do trabalho. São manipulações em que Penone, corroborando em certa medida a noção de despersonalização da arte, ecoa Duchamp (2008; 2009) e seus ready-mades a partir da etimologia da palavra invenção: "Minha posição não é, portanto, a de inventar, mas sim de indicar formas existentes. É um trabalho de indicação mais que de criação.

A palavra invenzione deriva do latim invenire, quer dizer, achar, encontrar. Ou seja, acha-se as coisas, não as inventa." (PENONE, 2017, p. 34). O que já existe, o que já está feito (ready-made) e que ele simplesmente encontra é, dentre tantas outras coisas, o devir escultor da natureza, sua tecnologia, sua técnica de esculpir - muitas vezes a si mesma, ao crescer. Mas o que Penone alega ao negar a dimensão animista da obra é que seu interesse se encerraria na forma do material.

Eu falaria sobre o problema da linguagem expressiva pois eu faço um trabatho que é baseado nos materiais. O princípio de equivalência entre pessoa, árvore e pedra [...] não define uma relação de poder entre as coisas, mas sim uma relação paritária. Em virtude desta relação paritária se confere dignidade ao material, à pedra, à árvore, à água, a todos os elementos e entra-se em uma lógica que efetivamente não está muito distante da lógica do animismo, ainda que não tenha nada a ver com 0 animismo. $O$ passo entre considerar os elementos thes conferindo dignidade e atribuir a eles uma vitalidade pode parecer breve, mas aquilo que eu faço é revelar a forma dos elementos. (PENONE, 2017, p. 33)

5 CÂMARA, M.; DAYRELL, J. G. Entrevista com Giuseppe Penone. ARS (São Paulo), [S. I.], v. 15, n. 29, p. 28-43, 2017. DOI: 10.11606/issn.2178-0447. ars.2017.123858. Disponivel em: https://www.revistas.usp.br/ars/article/view/123858. Acesso em: 9 abr. 2021. 

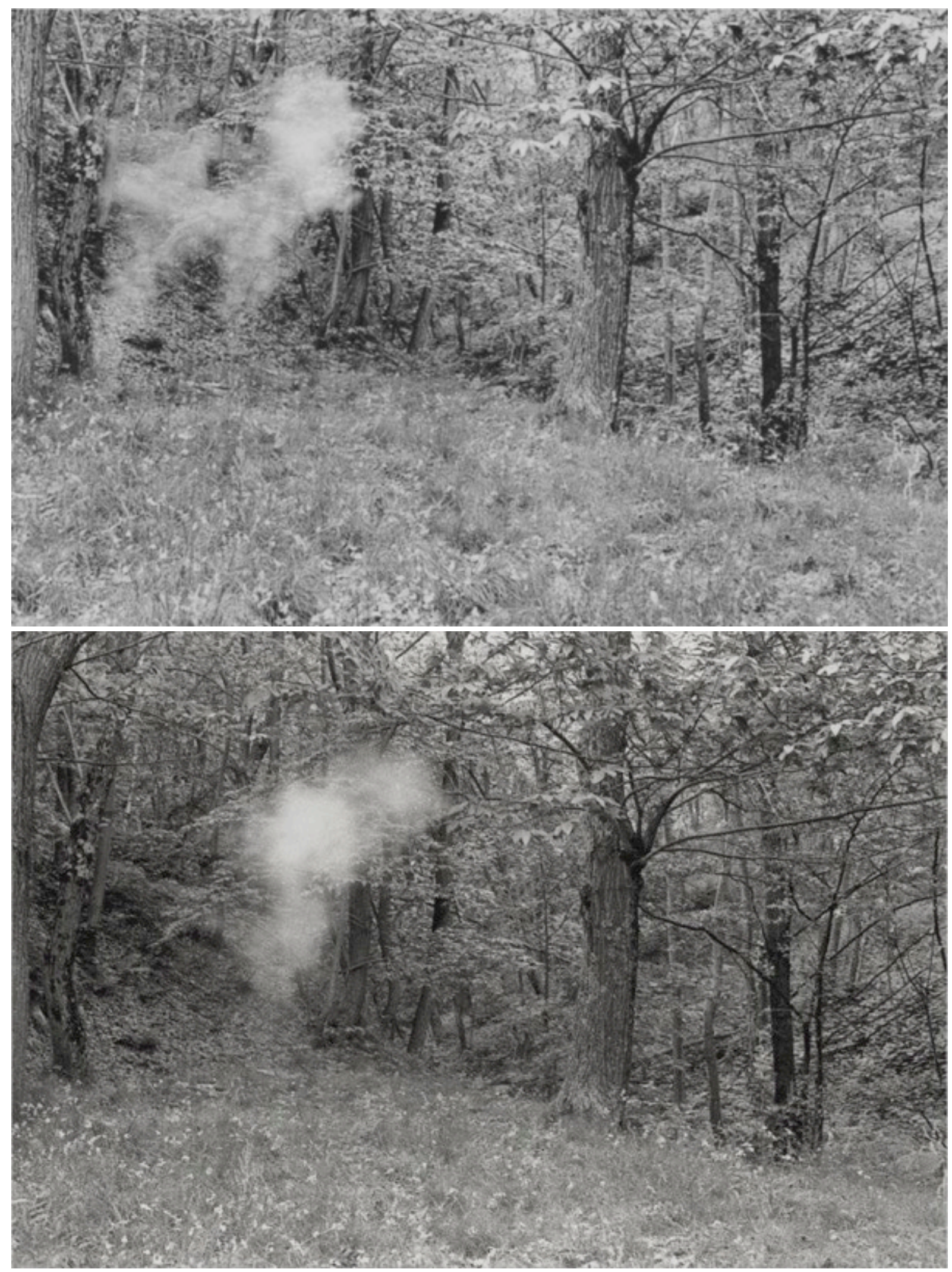

Figuras 2 e 3. Giuseppe Penone. Soffi, 1975. Collezione Privata. Fonte: @ Archivio Penone.

Ainda na entrevista, quando o perguntei sobre sua relação com o real, ele reiterou que se trata de uma relação física. Não me parece, no entanto, que nenhuma relação verdadeiramente paritária - tal qual a reivindicada por ele em sua obra - pos- 
sa estabelecer-se simplesmente no âmbito formal-matérico, mesmo por que a tecnologia implicada no devir escultor da natureza que ele, enquanto artista, encontra e articula, não é algo da ordem formal. Mas talvez esta insistência sobre sua obra ser ou não animista pouco venha ao caso. Na sequência da entrevista ele rapidamente supera esta questão para, finalmente, esclarecer sobre como, para ele, se dá de fato a relação com o real: "a realidade se dá, nos limites do infinito, em um ponto preciso." (PENONE, 2017, p. 35). Naquele momento ele apontou para uma obra que estava na parede logo atrás dele, Spoglia d'oro su spine d'acacia (bocca), e fez menção ao espaço negro que penetra nosso corpo quando fechamos os olhos:

Se você fecha os olhos e toca algo, não tem uma dimensão precisa, já que não está olhando ao mesmo tempo. A sensação de tocar é algo que ocupa o espaço da sua mente de um modo sem confins. [...] E esta é uma relação real com as coisas: o contato. (PENONE, 2017, p. 34-35).

Nesta obra temos esse beijo gigante que, dado de olhos fechados, nos envolve como um ambiente e faz com que este real infinito nos toque num ponto preciso, que é a boca6.

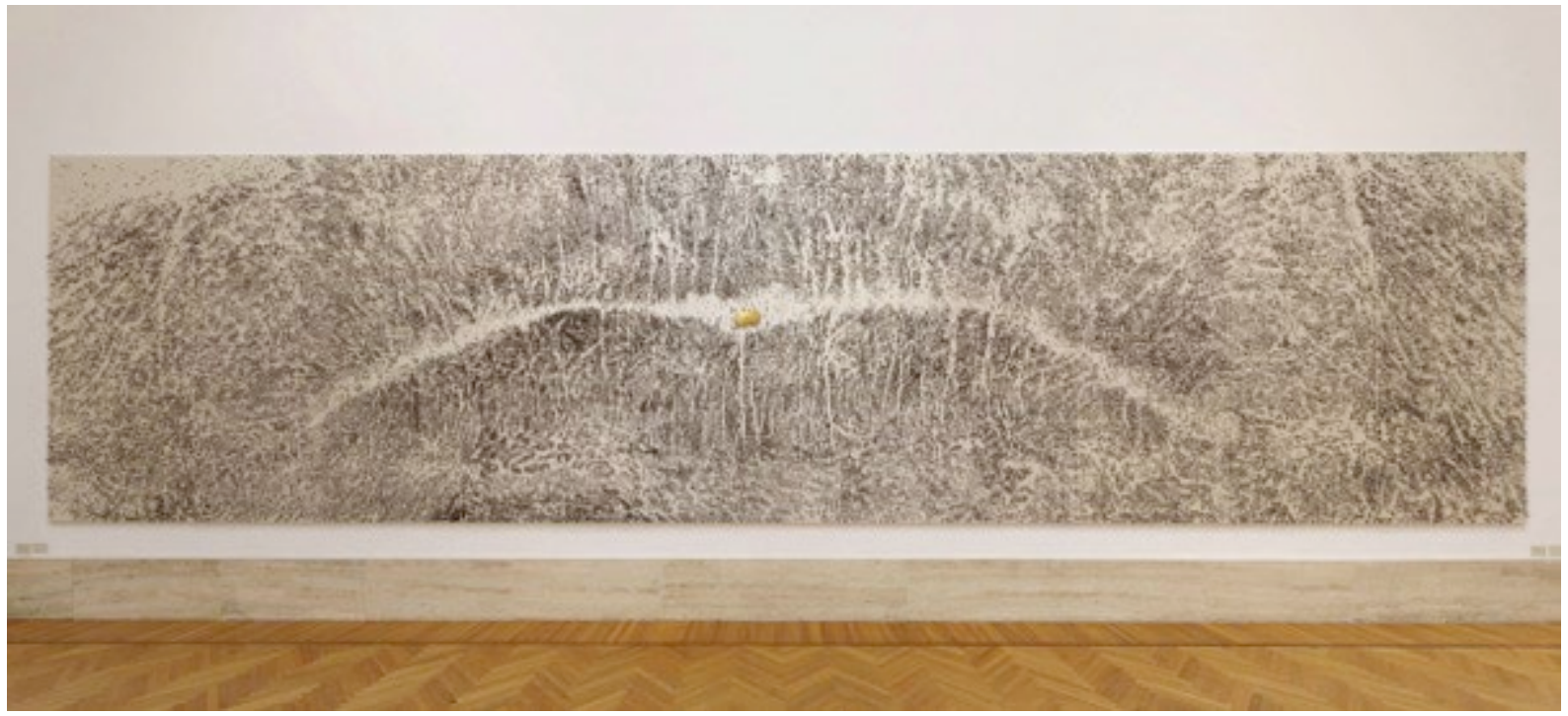

Figura 4. Giuseppe Penone, Spoglia d'oro su spine d'acacia (bocca), 2001. Collezione MAXXI, Roma (IT). Fonte: Cortesia do artista

6 Aideia de poética do contato, desenvolvida na minha tese, ainda que não tenha sido colocada em termos de real diz sobre este instante da experiência de um encontro que, no entanto, não precisa ser necessariamente físico, já que é tão matérico quanto transcendental. 

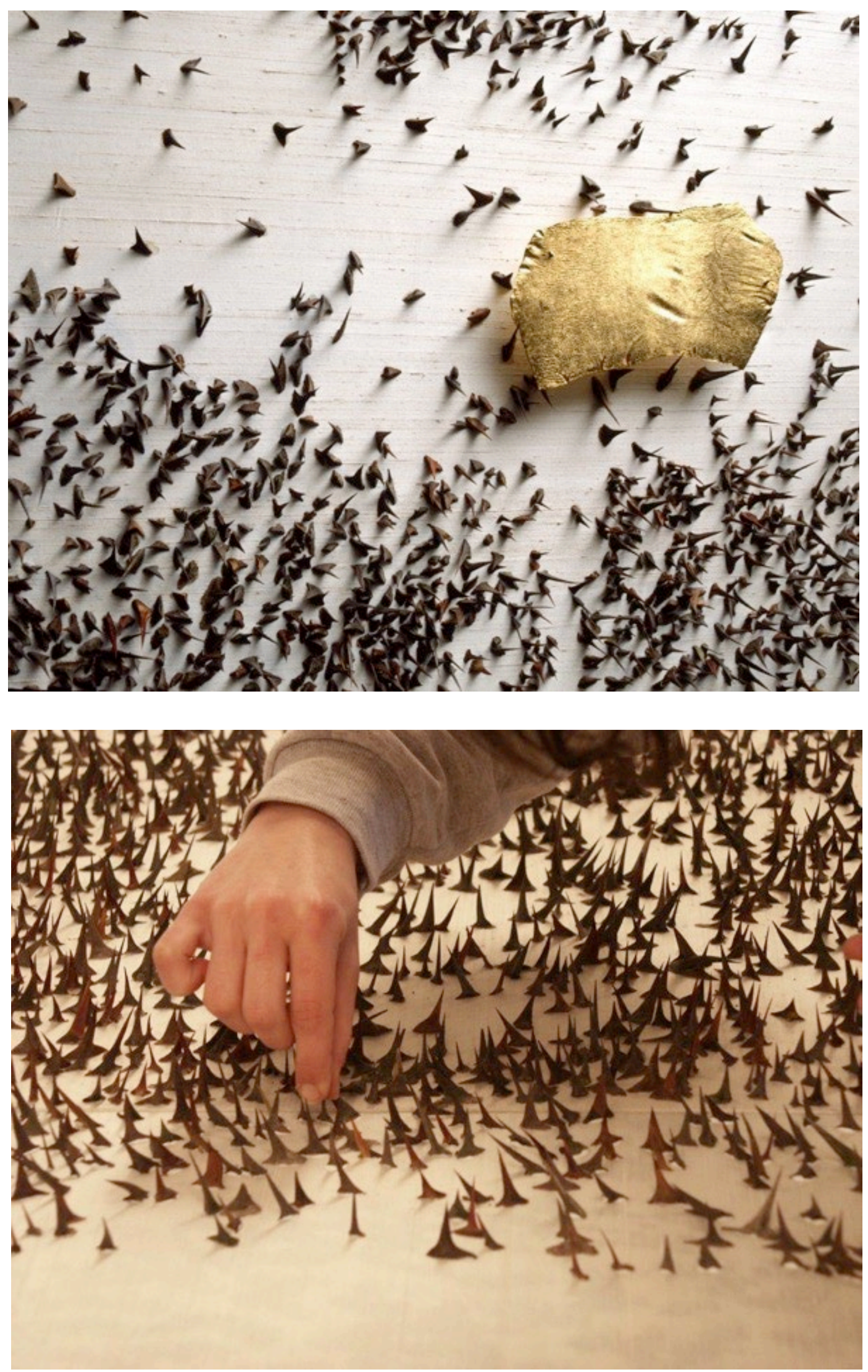

Figuras 5 e 6. Giuseppe Penone, Spoglia d'oro su spine d'acacia (bocca), 2001. Detalhe do processo de criação da obra. 
Recuperar os movimentos que precederam o advento da obra penoneana é, no entanto, imprescindível para a leitura de sua obra. Apesar de os artistas poveros terem suas especificidades, aquele movimento foi considerado por um dos críticos que mais admiro, Renato Barilli, tão sincrônico quanto a própria obra de Penone. Ao dizer sobre a Arte Povera, Barilli escreveu que este movimento retomava os preceitos matéricos do Informal, "sem no entanto, sentir-se na obrigação aprisionar-se perpetuamente aos materiais magmáticos, detritos, resíduos." (BARILLI apud CELANT, 2011, p. 130). A Arte Povera não poderia ser considerada contra-cultura, pois ela pretende posicionar-se em um lugar em que a noção de cultura é, por si só, um produto cultural, ou como bem disse Ginafranco Maraniello: a própria "natureza é, também ela, um produto da cultura." (MARIANIELLO apud PENONE, 2009, p. 7). E assim, a Arte Povera - e Penone talvez tenha sido, daquele movimento, quem o demonstrou de modo mais evidente - não pode sair da cultura pois ao voltar-se para a natureza, lá estará ela, a cultura, que não é privilégio de nenhuma espécie, mas está em toda parte. Importante seguirmos chamando atenção para a pobreza sobre a qual a Arte Povera diz: se trata da dissolução da dialética natureza e cultura com vistas a alcançar aquele estado que Penone não cansa de buscar, o estado de paridade. É interessante, portanto, verificar que a Arte Povera retoma do Teatro Povero, não só o nome, mas algumas noções enfatizadas por Jerzy Grotowski (1992), como a negação dos limites que impedem ao corpo de atingir um estado impulsional, não voluntário e sobretudo instintivo, conforme quer seu texto-manifesto Per um teatro povero. Me parece que esses limites tensionados por Grotowski não dizem de outra coisa senão sobre o limiar que ao mesmo tempo une e separa o homem do animal, já que, nunca é demais lembrar, foi precisamente através das limitações impostas ao corpo que se produziu a noção de humano desde períodos pré-helenísticos.

Em um sugestivo texto de Tommaso Trini, Nuovo alfabeto per corpo e materia?, de 1969, o crítico parece ecoar as ideias de Renato Barilli (1988a; 1988b), dizendo da não obrigatoriedade da Arte Povera declarar-se anti-tecnológica, já que natureza e cultura convergem em uma substancial unidade no movimento poverista. Podemos afirmar que dois dos legados fundamentais do Teatro para a Arte Povera são, portanto, a defesa da primazia do instinto sobre a racionalidade humana e a participação do espectador na ativação da obra - sendo esta última, claramente, uma derivação duchampiana. Não só o Teatro Povero, mas também a produção dos artistas da Arte Povera de um modo geral, buscaram, portanto, assim como faz sempre explicitamente a poética de Penone, recosturar a fratura entre natureza e cultura. Existe, no entanto, uma condição para que se possa pensar a superação dessa fratura e assumir a paridade entre eles: a saída de si, da posição de civilizado que, como bem disse Jean-Christophe Bailly "faz do sujeito, do artista, de cada homem, uma entidade separada que vive sobre um topo e olha o mundo à distância." (BAILLY apud PENONE, 2008, p. 64).

7 CONTE, 2010, p. 230. 0 texto citado pela professora Lara Conte foi reproduzido na última publicação sobre a Arte Povera organizada por Celant, de 2011 (TRINI apud CELANT, 2011, p. 108). TN de: [...] non ha bisogno di dichiararsi "anti-tecnologica". L'arte povera è un'arte che per il suo "orientamento nettamente antropologico" fa convergere "natura e cultura in una sostanziale unità, andando oltre la dimensione oggettuale, per sfuggire la mercificazione ed esplorare la temporalità del processo, la "creazione fluida in osmosi con il teatro". Le nuove istanze artistiche attingono infatti una nuova dimensione biologica di ricerca, dando vita a quello che il critico definisce "nuovo alfabeto per corpo e materia", che pone in risalto l'individuo, il suo corpo, il "suo operare ed essere nel mondo". 
Para concluir nosso comentário que antecede as traduções dos escritos de Penone, vejamos algumas ideias nesse sentido. A técnica que Grotowski propôs a partir de 1959 para fazer com o que o ator atingisse o estado impulsional foi, em suas palavras, uma "técnica de transe". Georges Bataille, por sua vez, para desenvolver sua noção de comunidade havia recorrido anos antes precisamente à ideia de êxtase (AGAMBEN, 2005). Para o filósofo Emanuele Coccia (2010; 2018; 2020), a própria percepção do mundo só é possível através do exílio sensível dos corpos. E ainda, a ideia de mimetismo e o princípio de correspondência que o antropólogo Roger Caillois desenvolveu nos textos "O louva-a-deus religioso"8 e "Mimetismo e psicastenia lendária", contidos em "O mito e o homem", livro de 1938, dizem de uma despersonalização através do processo de identificação com o espaço: "A identificação com o espaço é contemporânea à diminuição do sentimento da personalidade e da vida. [...] A vida recua um grau. O mundo tende à uniformidade." (CAILLOIS, 1980, p. 86). Caillois encara o mimetismo como uma atividade instintiva que tende a apaziguar a diferença entre o corpo do organismo e o ambiente.

Desindividualização ou despersonalização, como queiramos, a perda da vontade de ser e de preservar o seu ser que pode ser lida como uma vontade de retirada, de êxtase, a fim de formar um corpo - Bataille diria, talvez, uma comunidade - com o meio em que vive, ser esse meio, Ser rio. Se o espaço nos solicita constantemente, tanto a nós, quanto a todos os organismos vivos, aceita-se esta solicitação tornando-nos, como quer Emanuele Coccia, sensíveis e, como disse Bataille (1975), decapitados. Não mais sujeitos, mas pathos, fenômeno ou imagem a partir dos quais seremos infinitamente apropriáveis. Perene e mútuo atravessamento dos corpos do mundo, cuja irrevogável certeza é ser natureza. 


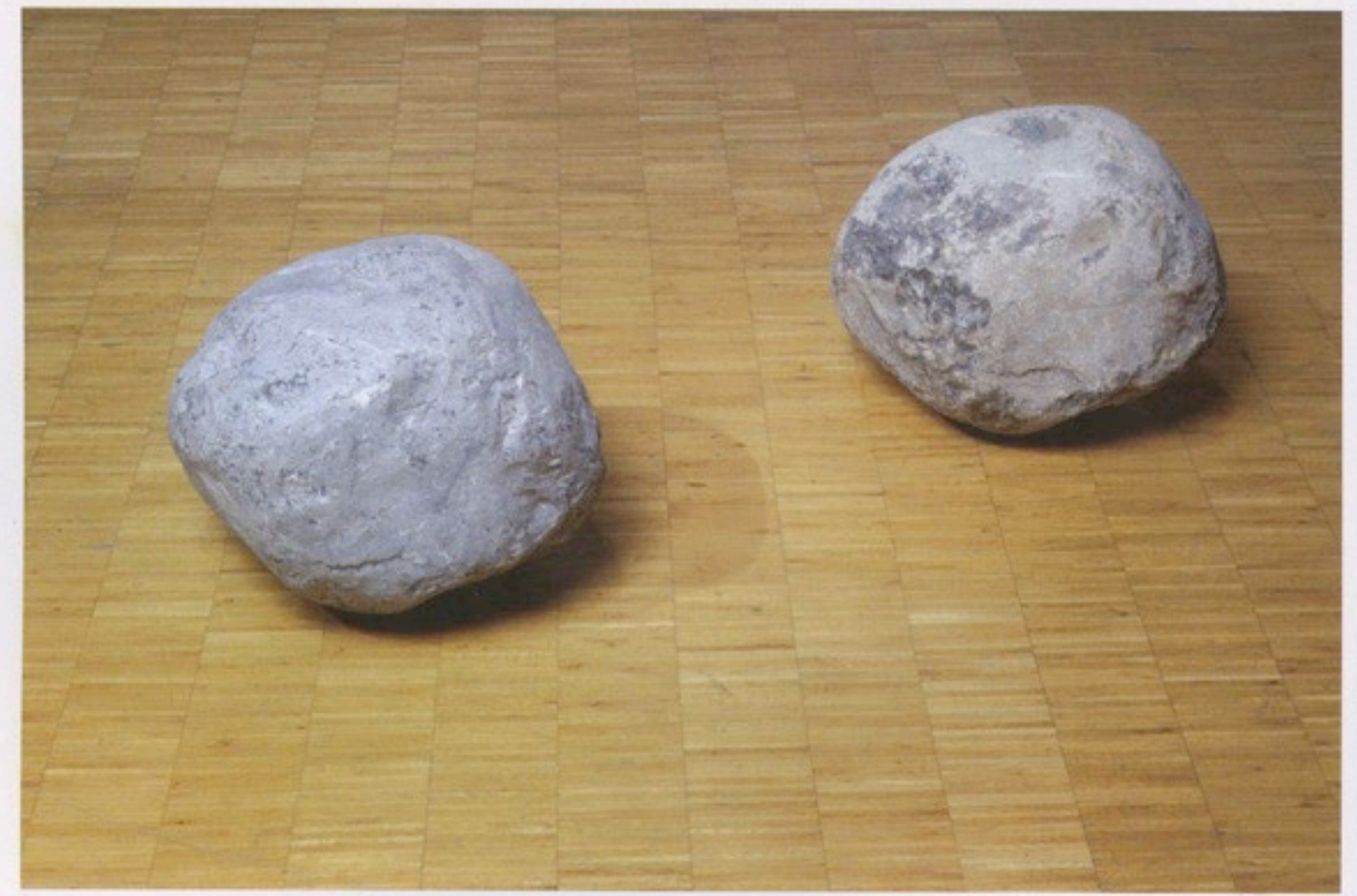

Figura 7. Giuseppe Penone. Essere fiume 1, 1981. Dallas. Fonte: Cortesia do artista.

\section{Escritos de Giuseppe Penone}

Tradução: Marina Câmara.

A necessidade de elaborar, de compreender a imagem que produzo me impele a tomar nota dos pensamentos cujo valor se completa somente ao lado dos trabalhos.

Fica incompleto o sentido dos meus escritos senão quando lidos pensando-se nas minhas obras.

O meu trabalho teve início na segunda metade dos anos sessenta, um momento de forte reação ao sistema político e social que não permitia a indiferença.

A forte crítica social era acompanhada pelo desejo de zerar os valores, a fim de poder reconstruir sobre bases de uma identidade reinventada.

A escolha de trabalhar com elementos naturais é a consequência lógica de um pensamento que excluía o produto da sociedade e que pesquisava relações de afinidade com a matéria.

A vontade de uma relação paritária entre a minha pessoa e as coisas é a origem do meu trabalho.

O homem não é espectador ou ator, mas simplesmente natureza. 
A história do homem está na palma da mão, na folha de videira impressa sobre a palma da mão.

A força de coesão entre as moléculas de uma gota d'água é o princípio da identidade do nosso corpo.

A obra é projetada no futuro, está ligada ao crescimento da árvore, à sua existência. A obra está em devir; para possuir a obra é preciso viver ao lado da árvore que da obra é a atriz. A mutação, o processo de crescimento da árvore é a experiência da obra de arte.

A árvore, perdido e consumado todo significado emocional, formal e cultural, parece um elemento vital em expansão, em proliferação e crescimento contínuo. À sua "força" aderiu uma outra "força", a minha. A sua reação é o trabalho.

Seus ramos e seu tronco se adaptam aos anéis das mãos, dos braços, das pernas, mas seus movimentos tendem a envergar no vazio os pesos reunidos à sua estrutura.

Agravando seu teso esforço em não perder o equilíbrio que se torna continuamente precário pela ação demolidora da força da gravidade, se une o empuxo do vento e a instabilidade do terreno que, desmoronando, torna seus movimentos similares àqueles de um patinador.

Sinto a respiração da floresta,

ouço o crescimento lento e inexorável da madeira, modelo a minha respiração sobre a respiração do vegetal, percebo o escorrer da árvore em torno daminha mão apoiada em seu tronco.

A modificada relação de tempo torna fluido o sólido e sólido o fluido. A mão afunda no tronco da árvore, que, pela velocidade do crescimento e plasticidade da matéria, é o elemento fluido ideal para ser plasmado. 
A árvore, edificando em vertical, busca continuamente

o equilíbrio e executa, com o número de seus ramos,

o peso das suas folhas e sua distribuição,

a mesma análise sobre o vazio conduzida pelo equilibrista

com os braços tesos.

Tesa em relação ao seu ritmo de crescimento, a árvore, depois de ter tentado evitar, se deslocando no espaço, os obstáculos que a ela eram colocados pela atividade do ambiente, para não reduzir os tempos de expansão e a sua estabilidade, os absorve.

...como a lama, aprendeu a engolir as pedras, as engloba e as torna parte da sua própria estrutura.

A pedra aguarda os movimentos vegetais.

É como um fragmento de mar.

Tem o mesmo valor visual da água que inclui as rochas marinhas

e lambe a costa mas, diferentemente

do mar, é ela que é, aos poucos, envolvida

pela fluida e lenta expansão vegetal.

[1968]

Uma concepção diferente sobre o tempo é a condição

para melhor captar a realidade da árvore em crescimento e sua fluidez.

Compartilhar a ação da árvore pressupõe

uma interpretação diferente da realidade.

Tal condição nos projeta em um imaginário novo,

rico de formas e sensações incomuns.

Se uma das funções da arte é a contínua releitura da realidade, mudar a concepção do tempo nos coloca na condição de rever

e recriar as convenções do real

e nos permite imaginar formas novas com novos valores.

Cada uma das coisas concebe e mensura o tempo com seus ritmos existenciais, biológicos, de formação e de existência.

A concepção do tempo que têm uma borboleta,

uma flor, uma árvore, um animal, um homem, uma pedra,

uma montanha, um rio, um mar,

um continente, um átomo produz a variedade infinita do pensamento

e das formas do universo. 


\section{Referências}

AGAMBEN, Giorgio. Bataille e o Paradoxo da Soberania. IN: CAPELA, Carlos Eduardo Schimidt e SCRAMIN, Susana. Revista Outra Travessia. A Exceção e o Excesso. Florianópolis, p. 91-94, 2005.

BARILLI, Renato. Informale, oggetto, comportamento. Volume primo. La ricerca artistica negli anni 50 e 60. Milão: Feltrinelli Editore, 1988a.

Informale, oggetto, comportamento. Volume secondo. La ricerca artistica negli anni \&apos;70. Milão: Feltrinelli Editore, 1988b.

BATAILLE, George. A parte maldita. Precedida de "A noção de despesa". Trad. Júlio Castañon Guimarães. Rio de Janeiro: Imago Editora, 1975.

CÂMARA, Marina, 1981- Giuseppe Penone: da história à pele do mundo. 2016. Tese (doutorado) - Universidade Federal de Minas Gerais, Escola de Belas Artes.

.; Dayrell, J. G. (2017). Entrevista com Giuseppe Penone. ARS (São Paulo), 15(29),

p. 28-43, 2017. DOI: https://doi.org/10.11606/issn.2178-0447.ars.2017.123858

CELANT, Germano (Org.). Arte povera. Storia e storie. Milão: Elect, 2011.

COCCIA, Emanuele. A vida sensível. Trad. Diego Cervelin. Florianópolis: Cultura e Barbárie, 2010.

A vida das plantas. Florianópolis: Cultura e Barbárie, 2018.

Metamorfoses. Rio de Janeiro: Dantes Editora, 2020.

CONTE, Lara. Materia, corpo, azione. Ricerche artistiche processuali tra Europa e Stati Uniti 1966-1970. Milão: Electa, 2010.

DUCHAMP, Marcel. Ingegnere del tempo perduto. Conversazione con Pierre Cabane. Trad. Angelica Tizzo. Milão: Abscondita, 2009.

Marcel Duchamp. Notes. Paris: Champs arts, 2008.

GROTOWSKI, Jerzy. Em busca de um teatro pobre. Trad. Aldomar Conrado. Rio de Janeiro: Civilização Brasileira, 1992.

PENONE, Giuseppe. Giuseppe Penone. Scritti 1968-2008. Bolonha: MAMbo - Istituzione Galleria d'Arte Moderna, IKON Gallery, 2009.

Giuseppe Penone. Roma: 2008. Catálogo de exposição, 29 jan-25 mar 2008, Académie de France à Rome, Villa Medici. 